\title{
A INFLUÊNCIA DAS CARACTERÍSTICAS DEMOGRÁFICAS DOS CONTADORES NO RECONHECIMENTO DOS GASTOS COM PESQUISA E DESENVOLVIMENTO
}

\author{
THE INFLUENCE OF DEMOGRAPHIC CHARACTERISTICS OF ACCOUNTANTS ON THE \\ RECOGNITION OF RESEARCH AND DEVELOPMENT EXPENDITURES
}

\section{Douglas Santos de Souza}

Faculdade de Tecnologia Nova Palhoça, Palhoça, SC, Brasil. E-mail: douglas.croqui@gmail.com

\section{Larissa Vitória Diel}

Faculdade de Tecnologia Nova Palhoça, Palhoça, SC, Brasil. E-mail: larissa.vitoriadiel@gmail.com

\section{Ernando Fagundes}

Universidade Federal de Santa Catarina, Florianópolis, SC, Brasil. E-mail: fagundes.ernando@gmail.com

\section{Rodrigo Rengel}

Universidade Federal de Santa Catarina, Florianópolis, SC, Brasil. E-mail: rengel.rodrigo@hotmail.com

\section{Fabricio Constante}

Faculdade de Tecnologia Nova Palhoça, Palhoça, SC, Brasil. E-mail: fabricio.constante@unigranrio.edu.br

\begin{abstract}
Resumo: O objetivo desta pesquisa é analisar se características demográficas dos contadores influenciam no reconhecimento dos gastos de Pesquisa e Desenvolvimento $(\mathrm{P} \& \mathrm{D})$ de seus clientes como ativo intangível ou como despesa. Para responder o objetivo foi aplicado um questionário com os contadores associados a FENACON do município de Palhoça/SC. A população deste estudo engloba 117 indivíduos e a amostra final totalizou 47 respostas, o equivalente a $40,17 \%$ da população. Trata-se de uma pesquisa descritiva e de levantamento de dados ou survey, quantitativa, e de natureza aplicada. Para atingir o objetivo do estudo, realizou-se estatísticas descritivas quanto às características dos participantes da pesquisa, assim como análises de percentuais de respostas. Por fim aplicou-se uma Regressão Logística afim de identificar a influência das características demográficas na tomada de decisão de reconhecer os gastos de P\&D como intangível ou despesa. Os resultados obtidos demonstraram que três variáveis independentes da pesquisa (características demográficas) influenciam na forma de reconhecimento de gastos na fase de P\&D. São as características: gênero para o reconhecimento como despesa; se o profissional é proprietário do escritório de contabilidade para reconhecimento como ativo intangível; e tempo de atuação do escritório de contabilidade, também para despesa. Conclui-se que a subjetividade deixada pelas normas contábeis faz com que o reconhecimento dos gastos com $\mathrm{P} \& \mathrm{D}$ não sejam padronizados entre os profissionais contábeis. Por fim, esta pesquisa contribui tanto com a teoria, uma vez que esta foi pioneira na verificação da influência das características demográficas quanto à classificaçáo destes gastos, como à prática, por servir como alerta aos contadores, de modo entender as tomadas de decisóes dos contadores, bem como apresentar a importância da constante atualização e continuação da educação destes profissionais.
\end{abstract}

Palavras chave: Características demográficas, Contadores, Gastos com P\&D, Ativo Intangível, Despesas. 


\begin{abstract}
The objective of this research is to analyze whether demographic characteristics of accountants influence the recognition of Research and Development $(R \& D)$ expenses of their clients as an intangible asset or as an expense. To answer the objective, a questionnaire was applied with the accountants associated with FENACON of the municipality of Palhoça/SC. The population of this study includes 117 individuals and the final sample totaled 47 responses, equivalent to $40.17 \%$ of the population. It is a descriptive research and data collection or survey, quantitative, and applied nature. To reach the study objective, descriptive statistics were performed on the characteristics of the participants of the study, as well as analyzes of percentages of responses. Finally, a Logistic Regression was applied to identify the influence of the demographic characteristics in the decision making of recognizing the $R \& D$ expenditures as intangible or expense. The results showed that three independent variables of the research (demographic characteristics) influence the form of recognition of expenses in the R\&D phase. They are the characteristics: gender for recognition as expense; if the professional is the owner of the accounting office for recognition as an intangible asset; and accounting practice time, also for expense. It is concluded that the subjectivity left by accounting standards means that the recognition of $\mathrm{R} \& \mathrm{D}$ expenses is not standardized among accounting professionals. Finally, this research contributes so much to the theory, since it was a pioneer in verifying the influence of the demographic characteristics as to the classification of these expenditures, as to the practice, by serving as an alert to the accountants, to understand the counters' decision making, as well as presenting the importance of the constant updating and continuation of the education of these professionals.
\end{abstract}

Keywords: Demographic characteristics, Accountants, R\&D expenses, Intangible assets, Expenses.

\title{
1 Introdução
}

A Pesquisa e Desenvolvimento (P\&D) corresponde a procura por conhecimento na criaçáo, produção e preparação do ativo, que nesta fase ou etapa normalmente é intangível. Os gastos na fase inicial de pesquisa devem ser reconhecidos como despesa (CPC 04, 2010). Entretanto, se estes gastos demonstrarem alguns aspectos como viabilidade técnica, intenção de usá-los e probabilidade de gerar benefícios econômicos futuros, os mesmos poderão ser reconhecidos como ativo intangível (PADOVEZE, 2017).

A contabilidade está em constantes mudanças, de modo que os contadores precisam acompanhar esta transformação, se adequar a este cenário com qualificação profissional e atualizar-se perante as diversas leis para superar as dificuldades que a contabilidade traz junto com tais modificaçóes (SOUZA; ASCENÇÃO; SOUZA, 2011). O contador auxilia nas tomadas de decisões do gestor da empresa, ao fornecer informaçôes relevantes. Desta forma, é necessário o bom preparo do profissional para identificação de possíveis erros e fraudes, como futuros e possíveis problemas (RESSER; PEREIRA, 2018). Em relação aos gastos com $\mathrm{P} \& \mathrm{D}$, classifica-los como despesa ou ativo intangível pode impactar no resultado apurado no período,

Devido à complexidade existente na contabilidade surgem dúvidas por parte dos contadores na classificação das contas contábeis. Com estas dúvidas, existe subjetividade na interpretação das normas e leis para a classificação das contas. A subjetividade é aquilo que é fundamental ao ser humano, é expressa em pensamentos, condutas, emoçóes e açôes. Os contadores, no decorrer do tempo e com as experiências profissionais adquiridas devem lidar de maneira adequada com a subjetividade (DAVEL; VERGARA, 
2014), haja vista que alguns fatores pessoais podem influenciar e ser determinantes para categorizar tais contas.

Desta forma, a questão norteadora desta pesquisa é: Características demográficas dos contadores influenciam na forma de reconhecimento dos gastos com P\&D de seus clientes? Para responder à questão proposta, tem-se por objetivo geral analisar se as características demográficas dos contadores influenciam no reconhecimento dos gastos de $\mathrm{P} \& \mathrm{D}$ dos seus clientes como ativo intangível ou como despesa. A pesquisa se delimita aos contadores associados à FENACON do município de Palhoça/SC.

Justifica-se o estudo em virtude da necessidade de analisar se as características dos contadores influenciam no reconhecimento dos gastos com P\&D, análise esta inexplorada pela literatura até o presente momento. Pode este ser um instrumento para auxiliar nas tomadas de decisóes dos contadores, contribuindo desta maneira com a prática profissional da atividade. Contribui-se no âmbito social, devido a possibilidade de existir profissionais do segmento analisado que não possuem hábito de busca por maiores qualificaçóes e educação continuada em sua área. Assim a pesquisa torna-se um meio para apresentar atualizaçôes e evitar possíveis desacordos com a legislação vigente.

A pesquisa é dividida em cinco seçôes a contar com esta introdução. A segunda seção aborda o embasamento teórico e estudos apropriados ao tema. Na terceira, apresenta-se o enquadramento metodológico e a amostra estudada e na quarta seção as análises e resultados obtidos com o estudo. Encerra-se na quinta seção com as consideraçóes finais, seguida das referências bibliográficas.

\section{Fundamentação teórica}

\subsection{Ativo intangível gerado internamente e classificação contábil}

Os ativos de uma empresa são recursos controlados de resultados passados e que possuem uma relevante expectativa de benefícios econômicos futuros, para a empresa (CPC 00 (R2), 2019).

No ano de 2007, a então Lei no 6.404/76 modificou-se com a Lei no $11.638 / 07$, em que se alterou o termo ativo diferido para ativo intangível. Ativo diferido abordava as aplicaçóes de recursos em despesas que contribuíam para a formação do resultado de mais de um exercício social. Era uma particularidade do ativo diferido o ativamento de uma despesa, a postergar seu lançamento como despesa para exercícios futuros. Era um procedimento de amortização de uma despesa em mais de um exercício contábil, de forma a distribuir ao longo de vários anos esses gastos, na intenção de que esses gastos poderiam gerar parte das receitas futuras (BRASIL, 1976; 2007).

Ativo intangível é um ativo não monetário identificável sem substância física. São considerados ativos intangíveis os direitos que tenham por objeto bens incorpóreos destinados à manutenção da companhia ou praticados com esse propósito. Classificados como direitos incorpóreos (sem corpo físico) que têm valor econômico para a empresa e que elaboram resultados futuros, tais exemplos de ativos intangíveis: marcas, patentes e direitos autorais (CPC 04, 2010).

$\mathrm{O}$ ativo intangível pode ser identificado quando possível separar os gastos dos outros ativos da empresa, também no momento for vendido, transferido, licenciado, alugado ou trocado, ou, resultar 
tanto em direitos contratuais como em outros direitos legais, mesmo se tais direitos serem transferíveis ou separáveis da empresa. A empresa tem o controle de um ativo intangível ao conseguir obter benefícios econômicos futuros gerados por este ativo (PADOVEZE, 2017).

Os ativos intangíveis gerados internamente na fase de pesquisa devem ser classificados como despesa. No entanto, no desenvolvimento podem ser classificados como despesas ou como um ativo, dependendo do fato de atenderem os critérios citados no CPC 04. Impossibilitado de distinguir uma fase da outra, considera-se incorrido na fase de pesquisa (MARION, 2013). Ao não atenderem aos critérios de reconhecimento expostos pelo CPC 04 classifica-se como despesa, caso contrário, classifica-se como ativo (CPC 04, 2010).

O reconhecimento inicial do intangível é pelo seu custo. O custo do ativo intangível gerado internamente inclui todos os gastos diretamente atribuíveis, fundamentais à criação, produção e preparação do ativo intangível para ser capaz de funcionar de forma esperada pela administração (CPC 04, 2010), tais como: materiais e serviços consumidos ou aplicados no seu desenvolvimento; taxas de registro de direito legal, custos de salários e encargos sociais dos empregados relacionados diretamente ao desenvolvimento do ativo intangível e amortização de patentes e licenças utilizadas na geração desse ativo (CPC 04, 2010).

O custo do ativo intangível adquirido compreende o seu preço de compra, acrescentado dos impostos de importação e tributos não recuperáveis sobre a compra, e quais outros custos propriamente atribuíveis à elaboraçáo desse ativo para a destinação proposta, tais como salários, encargos sociais e honorários dos empregados e profissionais diretamente relacionados com o ativo intangível para que ele fique em condições de operação (PADOVEZE, 2017).

Em casos nos quais os ativos intangíveis são decorrentes de pesquisa não se deve reconhecê-los, pois a empresa não está apta a afirmar se sua existência gerará benefícios econômicos futuros. Todavia, os gastos com pesquisa (ou da fase de pesquisa e projeto interno) devem ser reconhecidos como despesas ao serem incorridos (CPC 04, 2010). Os gastos deverão ser ativados no grupo de intangíveis de acordo com os seguintes critérios: (i) viabilidade técnica; (ii) intenção de conclusão para venda ou uso; (iii) ter capacidade de uso ou venda; (iv) gerar benefícios econômicos futuros; (v) disponibilidade de recursos técnicos e financeiros; e (vi) capacidade de mensurar com confiabilidade os gastos.

Para demonstrar como um ativo intangível gerará benefícios econômicos futuros, seja de forma isolada, sejam de forma conjunta com outros ativos, deve-se seguir as diretrizes estabelecidas pelo CPC 01. No reconhecimento do ativo intangível na fase de desenvolvimento, tanto interno como externo, existe uma subjetividade por conta da complexibilidade que há na mensuração dos ativos.

A subjetividade é um ponto forte ao se tratar da tomada de decisão, pois a decisão faz parte da vida de todos os indivíduos, ais quais estáo presentes em vários aspectos e momentos da vida. Como no âmbito profissional, na qual as características podem ser fator relevante e as diferenciações podem afetar nas tomadas de decisões, capaz de influenciarem em um fato considerável (FUJI; SLOMSKI, 2003).

$\mathrm{Na}$ contabilidade, a subjetividade leva em consideraçáo as percepçôes do profissional relativas a fatores econômicos na identificação e mensuração de eventos que devem ser informados na contabilidade (FUJI; SLOMSKI, 2003). Em relação a mensuração impessoal, dificilmente se consegue separar, a pessoa 
das crenças e a cultura do mensurador. $\mathrm{O}$ ato de mensurar pode sofrer influências da experiência, cultura e crenças do mensurador, pois a lei possibilita certa subjetividade (MELLO; ARAUJO, 2015).

Um tópico relevante é o tratamento dos ativos intangíveis, com inúmeras mudanças tecnológicas, existe a falta de reconhecimento de alguns, principalmente pelo grau de subjetividade que há no momento da mensuração desses ativos (FUJI; SLOMSKI, 2003).

Ademais, características do profissional contábil podem ser relevantes no comportamento do contador na classificação de gastos com P\&D de seus clientes.

\subsection{Caracteristicas do profissional contábil}

As características que envolvem o profissional contábil são relevantes perante o desempenho de suas funçôes. Estas podem interferir na vida profissional de maneira positiva ou negativa, sendo que a integridade ética em algumas situaçóes pode agir com divergência, o que varia de cada profissional. Desta forma, tais características podem influenciar na tomada de decisóes. Como se trata de uma particularidade, há diversos profissionais com diferentes pensamentos, ideologias, havendo a possibilidade de gerar conflitos internos, e estes acabam por criar dificuldades, como por exemplo: na tomada de decisóes para a solução de problemas de forma ágil, eficiente e eficaz (CUNHA; COLARES, 2013).

Características demográficas auxiliam a estudar a estrutura da população em sua composição, diversos aspectos podem ser analisados, tais como: a faixa etária, gênero, grau de instrução, faixa de renda, situação financeira e período de experiência profissional, as quais podem influenciar na tomada de decisão (GAVA; VIEIRA, 2006).

A faixa etária e o gênero de um indivíduo podem ser aspectos relevantes para identificar possíveis diferenças de comportamento, por se contemplarem hábitos diferentes, podendo haver uma distinção em uma tomada de decisão (CAPPELLE ET AL., 2004).

A qualificação profissional é fundamental para a área contábil, haja vista, que para ser contador é necessária a formação na área e o registro no Conselho Regional de Contabilidade (CRC). Deste modo, o grau de instruçáo do profissional, da mesma maneira que o período de experiência como contador, pode influenciar diretamente no reconhecimento dos gastos com pesquisa e desenvolvimento (PORTAL DA CONTABILIDADE, 2018).

Alguns profissionais podem possuir obrigaçóes fazendo com que sua renda esteja totalmente comprometida, com inúmeros gastos, o que deixa esse profissional com sua situação financeira desequilibrada. Esse fato pode fazer com que o contador em questão tenha alguns receios no momento do reconhecimento dos gastos com pesquisa e desenvolvimento ou até mesmo em uma tomada de decisão, pois essas características pessoais podem afetar suas decisóes no ambiente profissional (REIS, 2008).

\subsection{Estudos relacionados}

Com base nas seguintes palavras-chaves: gastos com pesquisa e desenvolvimento, reconhecimento dos gastos com P\&D, mensuração dos gastos com pesquisa e desenvolvimento, buscou-se pesquisas dos 
últimos 10 anos sobre o tema abordado. Apresenta-se na Tabela 1 estudos relacionados, destacando os autores, objetivo, procedimentos metodológicos e os respectivos resultados de suas pesquisas.

Tabela 1 - Estudos relacionados

\begin{tabular}{|c|c|c|c|}
\hline $\begin{array}{l}\text { Autores } \\
\text { (Ano) }\end{array}$ & Objetivo & $\begin{array}{l}\text { Procedimentos } \\
\text { Metodológicos }\end{array}$ & Resultados \\
\hline $\begin{array}{l}\text { Barsch } \\
\text { e Souza } \\
(2018)\end{array}$ & $\begin{array}{l}\text { Identificar as características } \\
\text { da evidenciação da fase de } \\
\text { pesquisa e desenvolvimento } \\
\text { de ativos intangíveis nas } \\
\text { companhias de capital aberto } \\
\text { brasileiras. }\end{array}$ & $\begin{array}{l}\text { A pesquisa se } \\
\text { classifica como } \\
\text { documental }\end{array}$ & $\begin{array}{l}\text { Os autores observaram que são pouco divulgados os } \\
\text { detalhamentos e composição dos gastos com pesquisa } \\
\text { e desenvolvimento. Pode-se inferir que as companhias } \\
\text { abertas estudadas pouco evidenciam informações } \\
\text { relacionadas aos intangíveis gerados internamente, } \\
\text { sendo precária a divulgação delas. }\end{array}$ \\
\hline $\begin{array}{l}\text { Beuren, } \\
\text { Theiss e } \\
\text { Sant'ana } \\
(2013)\end{array}$ & $\begin{array}{l}\text { Examinar o conservadorismo } \\
\text { contábil no reconhecimento } \\
\text { de ativos intangíveis } \\
\text { em fase de pesquisa e } \\
\text { desenvolvimento das } \\
\text { empresas da B3. }\end{array}$ & $\begin{array}{l}\text { Caracteriza-se } \\
\text { como pesquisa } \\
\text { documental, } \\
\text { descritiva. }\end{array}$ & $\begin{array}{l}\text { Os resultados mostram que no período analisado } \\
\text { ocorreu conservadorismo contábil nas empresas } \\
\text { pesquisadas. Todavia, não se constatou relação positiva } \\
\text { do conservadorismo contábil e dos ativos intangíveis } \\
\text { em fase de pesquisa e desenvolvimento com tamanho, } \\
\text { alavancagem, setor e nível de governança corporativa } \\
\text { das empresas. }\end{array}$ \\
\hline $\begin{array}{l}\text { Rodrigues, } \\
\text { Elias e } \\
\text { Campos } \\
(2015)\end{array}$ & $\begin{array}{l}\text { Verificar a relevância da } \\
\text { informação contábil Pesquisa } \\
\text { e Desenvolvimento em } \\
\text { empresas listadas na B3 no } \\
\text { período de } 2003 \text { a } 2012 \text { por } \\
\text { meio do valor de mercado. }\end{array}$ & $\begin{array}{l}\text { O estudo é } \\
\text { descritivo }\end{array}$ & $\begin{array}{l}\text { Os resultados mostraram que pesquisa e } \\
\text { desenvolvimento não era uma informação relevante } \\
\text { para o investidor do mercado brasileiro antes da } \\
\text { convergência internacional. Após a obrigatoriedade do } \\
\text { CPC a informação com P\&D nas demonstraçóes das } \\
\text { empresas listada na bolsa de valores de São Paulo (B3), } \\
\text { mostrou-se relevante para o investidor. }\end{array}$ \\
\hline $\begin{array}{l}\text { Camargo, } \\
\text { et al. } \\
(2016)\end{array}$ & $\begin{array}{l}\text { Analisar a influência do } \\
\text { investimento em P\&D no } \\
\text { desempenho organizacional. }\end{array}$ & $\begin{array}{l}\text { Caracteriza-se } \\
\text { como descritiva } \\
\text { explicativa, } \\
\text { documental, } \\
\text { com análise } \\
\text { quantitativa dos } \\
\text { dados. }\end{array}$ & $\begin{array}{l}\text { Com quatro períodos pesquisados nos setores de } \\
\text { tecnologia e Indústria, náo foi possível identificar } \\
\text { efeitos superiores, entre as empresas que haviam } \\
\text { investido em P\&D e aquelas que náo haviam } \\
\text { investido. Com relaçáo aos valores dos Coeficientes } \\
\text { de P\&D }(1,22) \text {; P\&Dt-1 }(1,23), \mathrm{P} \& \mathrm{Dt}-2 \text {, o qual em } \\
\text { todos os períodos da série de dados apresentou se com } \\
\text { coeficientes negativos, isto indica que o investimento } \\
\text { em P\&D impacta negativamente no ROA }\end{array}$ \\
\hline $\begin{array}{l}\text { Oshita, et } \\
\text { al. (2016) }\end{array}$ & $\begin{array}{l}\text { Verificar se as empresas, } \\
\text { brasileiras listadas na B3, que } \\
\text { usufruem do benefício fiscal } \\
\text { de inovação capitalizaram } \\
\text { investimentos em } \\
\text { desenvolvimento tecnológico } \\
\text { enquanto ativo intangível. }\end{array}$ & $\begin{array}{l}\text { Caracteriza-se } \\
\text { como descritiva }\end{array}$ & $\begin{array}{l}\text { Conclui-se que as empresas utilizam o benefício } \\
\text { apenas para realizar melhorias de processo por meio de } \\
\text { atividade industrial básica e serviços de apoio técnico, } \\
\text { às quais não são atividades que possuem impacto } \\
\text { em relação à inovação, portanto, não geram ativos } \\
\text { intangíveis por meio da pesquisa e desenvolvimento. }\end{array}$ \\
\hline
\end{tabular}

Fonte: Elaborado pelos autores (2019).

Portanto, foram encontrados cinco artigos, publicados entre os períodos de 2013 a 2018, que auxiliaram na fundamentação da pesquisa. Esta pesquisa diferencia-se das anteriores por buscar relacionar características demográficas com o comportamento dos contadores diante de situaçóes de subjetividade na classificação dos gastos com P\&D. 


\section{Procedimentos metodológicos}

A abordagem da pesquisa é quantitativa. Quanto à sua natureza, esta pesquisa é aplicada por objetivar gerar conhecimentos para a aplicação prática e dirigida à solução de problemas específicos (OTANI; FIALHO, 2011). Trata-se ainda de um estudo descritivo e assume a forma de levantamento ou survey. $\mathrm{O}$ estudo foi realizado com os contadores do município de Palhoça/SC associados à FENACON. A população deste estudo engloba 117 indivíduos e a amostra final totalizou 47 respostas, o equivalente a $40,17 \%$ da população.

Nesta pesquisa, tem-se a variável dependente e a variável independente. A variável dependente corresponde aos posicionamentos dos contadores diante de cada decisão apresentada, nas quais podiam optar por classificar os gastos com $\mathrm{P} \& \mathrm{D}$ em ativo intangível ou como despesa. Já as variáveis independentes correspondem às características demográficas dos profissionais contábeis, como o gênero, faixa etária, situação financeira, tempo de atuação do profissional e dos escritórios, bem como o número de pessoas que trabalham neles.

A coleta de dados foi realizada a partir de um questionário elaborado pelos autores, estabelecendo cenários possíveis a partir dos critérios de classificação elencados pelo CPC 04. Este questionário foi testado com 11 alunos de uma turma de última fase do curso de Ciências Contábeis, o que demandou pequenos ajustes no texto de forma que o mesmo se tornasse mais claro e que culminou na versão aplicada aos respondentes.

O questionário é formado por dois blocos. No primeiro bloco éidentificado o perfil dos respondentes, verificado por meio de perguntas pessoais, buscando-se levantar as características demográficas dos contadores. O segundo bloco do questionário baseia-se no CPC 04 . Os contadores foram informados de que não há respostas certas ou erradas, devendo ele optar de acordo com sua experiência profissional. As questóes elaboradas são situaçóes de reconhecimento dos gastos com desenvolvimento, em que estes gastos têm a possibilidade de gerar benefícios econômicos futuros. O profissional para fazer este reconhecimento tem a opção de escolha de colocar estes gastos como despesa ou como ativo intangível, julgando essa possibilidade de gerar benefícios econômicos futuros como provável ou não, conforme apresenta-se na Tabela 2.

Tabela 2 - Instrumento de pesquisa

\begin{tabular}{c|l}
\hline Questáo & \multicolumn{1}{c}{ Abordagem } \\
\hline \multirow{2}{*}{ Q01 } & $\begin{array}{l}\text { Você, como contador de uma empresa farmacêutica, precisa tomar uma decisão referente aos gastos na } \\
\text { fase de desenvolvimento de um medicamento. Foi constatado que há possibilidade de esse medicamento } \\
\text { gerar benefícios econômicos futuros. Sendo o gasto com o desenvolvimento deste medicamento de R\$ } \\
1.000 .000,00, \text { você reconheceria esse gasto como Despesa ou como Ativo Intangível? }\end{array}$ \\
\hline \multirow{2}{*}{ Q2 } & $\begin{array}{l}\text { Os gastos com o desenvolvimento de um website em uma empresa, apresentam um determinado valor. O } \\
\text { website possui uma interface onde o cliente pode entrar em contato com a empresa e visualizar os produtos } \\
\text { oferecidos, o que possibilita gerar benefícios econômicos futuros. O website náo possui vida útil definida. } \\
\text { Você como contador, reconheceria o valor gasto no desenvolvimento do website como Despesa ou como } \\
\text { Ativo Intangível? }\end{array}$ \\
\hline
\end{tabular}




\begin{tabular}{c|l}
\hline Q03 & $\begin{array}{l}\text { Uma empresa está realizando uma pesquisa sobre determinado medicamento para a gripe A. O valor de } \\
\text { gastos com pesquisa foi de R\$ 300.000,00 e na fase de desenvolvimento foi de R\$ 150.000,00, havendo a } \\
\text { possibilidade de gerar benefícios econômicos futuros para a empresa. Você como contador, reconheceria os } \\
\text { gastos de R\$ 150.000,00 como uma Despesa ou como um Ativo Intangível? }\end{array}$ \\
\hline Q04 & $\begin{array}{l}\text { Na empresa Silva Tecnologia LTDA, está se criando um software, tendo sido investido um valor de R\$ } \\
700.000,00 \text { relacionado a gastos com P\&D. Neste valor já está incluso a fase de pesquisa e desenvolvimento. } \\
\text { A empresa Silva Tecnologia LTDA, identificou que há possibilidade de gerar benefícios econômicos futuros } \\
\text { na fase de desenvolvimento deste novo software. Você como contador, reconheceria como Despesa ou como } \\
\text { Ativo Intangível? }\end{array}$ \\
\hline Q05 & $\begin{array}{l}\text { A empresa Mais Tecnologia LTDA, está desenvolvendo um novo dispositivo. Este dispositivo já passou da fase } \\
\text { de pesquisa e agora encontra-se na fase de desenvolvimento. O dispositivo foi criado para a venda comercial } \\
\text { onde há possibilidade de gerar benefícios econômicos futuros. Você como contador, reconheceria os gastos } \\
\text { durante a fase do desenvolvimento como Despesa ou como Ativo Intangível? }\end{array}$ \\
\hline
\end{tabular}

Nota: Entende-se que as variáveis acima referem-se à: Q01 = Questão 01; Q02 = Questão 02; Q03 = Questão 03; Q04 = Questão 04; Q05 = Questáo 05.

Fonte: Elaborado pelos autores (2019).

Após etapa de coleta, os dados foram tabulados, analisados e interpretados para alcançar o objetivo da pesquisa. Organizou-se primeiramente em planilhas eletrônicas do Microsoft Excel. Após a codificação, realizou-se as estatísticas descritivas a respeito das características dos participantes da pesquisa, assim como análises de percentuais de respostas. Por fim aplicou-se uma Regressão Logística, buscou-se a partir desta verificar a probabilidade de ocorrência de um evento dicotômico (FÁVERO; FÁVERO, 2016). Utilizouse o software RStudio , para realização da regressão logística a partir da função base glm2.

\section{Análise e discussão dos dados}

\subsection{Estruturação e estatística descritiva dos dados}

Buscou-se por meio da análise estatística descritiva identificar o perfil dos respondentes e dos escritórios que estes atuam $(\mathrm{n}=47)$, quanto ao (i) gênero, (ii) faixa etária, (iii) grau de instrução, (iv) faixa de renda, (v) percepção da situação financeira própria, (vi) tempo de atuação na profissão contábil, (vii) se é proprietário ou não do escritório em que atua, (viii) tempo de atuação no escritório e (ix) quantidade de colaboradores no escritório. A Tabela 3 apresenta as três primeiras destas características.

Tabela 3 - Gênero, faixa etária e grau de instrução

\begin{tabular}{|c|c|c|c|c|c|c|c|c|}
\hline \multirow{2}{*}{$\begin{array}{r}\text { Gênero } \\
\text { Masculino }\end{array}$} & \multicolumn{2}{|c|}{ Freq. (\%) } & \multirow{2}{*}{$\begin{array}{l}\text { Faixa Etária } \\
\text { Até } 25 \text { anos }\end{array}$} & \multicolumn{2}{|c|}{ Freq. (\%) } & \multirow{2}{*}{$\begin{array}{l}\text { Grau de instruçáo } \\
\text { Ensino Técnico }\end{array}$} & \multicolumn{2}{|c|}{ Freq. (\%) } \\
\hline & 22 & $46,8 \%$ & & 6 & $12,8 \%$ & & 1 & $2,1 \%$ \\
\hline \multirow[t]{4}{*}{ Feminino } & 25 & $53,2 \%$ & De 26 a 30 anos & 8 & $17 \%$ & Graduação & 22 & $46,8 \%$ \\
\hline & & & De 31 a 35 anos & 11 & $23,4 \%$ & Especialização & 18 & $38,3 \%$ \\
\hline & & & De 36 a 40 anos & 9 & $19,1 \%$ & Mestrado & 6 & $12,8 \%$ \\
\hline & & & Mais de 41 anos & 13 & $27,7 \%$ & Doutorado & 0 & $0 \%$ \\
\hline Total & 47 & $100 \%$ & Total & 47 & $100 \%$ & Total & 47 & $100 \%$ \\
\hline
\end{tabular}

Fonte: Elaborado pelos autores (2019). 
Em relação ao gênero observa-se certo equilíbrio, embora a maior parcela da amostra (53,2\%), é formada por mulheres. Nota-se que quanto à idade dos respondentes que não houve predomínio absoluto de nenhuma faixa etária, destaca-se contadores acima de 41 anos (27,7\%), em seguida a faixa de 31 a 35 anos $(23,4 \%)$. O grau de instrução dos respondentes, como esperado apresenta grande qualificação da amostra analisada, devido ao fato de ser uma profissão regulamentada e que exige nível superior para sua execução. Deste modo, percebe-se que apenas 1 respondente não possui graduação, fato este que se deve em relação ao ensino técnico que é compatível para a realização da atividade profissional para aqueles que detinham credenciamento junto ao CRC até 01 de junho de 2015. A Tabela 4, destaca a faixa de renda, a percepção da situação financeira própria e o tempo de atuação na profissão contábil.

Tabela 4 - Faixa de renda, percepção da situação financeira própria e tempo de atuação na profissão contábil

\begin{tabular}{|c|c|c|c|c|c|c|c|c|}
\hline \multirow{2}{*}{$\begin{array}{l}\begin{array}{c}\text { Faixa de } \\
\text { renda }\end{array} \\
\text { Até } 2 \mathrm{SM}\end{array}$} & \multicolumn{2}{|c|}{ Freq. (\%) } & \multirow{2}{*}{$\begin{array}{l}\begin{array}{c}\text { Percepçáo da } \\
\text { situaçáo financeira } \\
\text { própria }\end{array} \\
\mathrm{ME}\end{array}$} & \multicolumn{2}{|c|}{ Freq. (\%) } & \multirow{2}{*}{$\begin{array}{c}\begin{array}{c}\text { Tempo de atuaçáo } \\
\text { na profissáo } \\
\text { contábil }\end{array} \\
\text { Até } 2 \text { anos }\end{array}$} & \multicolumn{2}{|c|}{ Freq. (\%) } \\
\hline & 6 & $12,8 \%$ & & 3 & $6,4 \%$ & & 5 & $10,6 \%$ \\
\hline De 2 a 4 SM & 16 & $34 \%$ & $\mathrm{PE}$ & 4 & $8,5 \%$ & De 3 a 5 anos & 7 & $14,9 \%$ \\
\hline De 4 a 6 SM & 11 & $23,4 \%$ & $\mathrm{FE}$ & 33 & $70,2 \%$ & De 6 a 10 anos & 17 & $36,2 \%$ \\
\hline De 6 a 8 SM & 7 & $14,9 \%$ & FBS & 7 & $14,9 \%$ & Acima de 10 anos & 15 & $31,9 \%$ \\
\hline Mais de 8 SM & 7 & $14,9 \%$ & & & & Não atuam na área & 3 & $6,4 \%$ \\
\hline Total & 47 & $100 \%$ & Total & 47 & $100 \%$ & Total & 47 & $100 \%$ \\
\hline
\end{tabular}

Nota: As variáveis acima destacadas se referem: $\mathrm{SM}$ = Salário mínimo com base no valor de $\mathrm{R}$ \$ 954; ME = Muito endividado; $\mathrm{PE}=$ Pouco endividado; FE = Financeiramente equilibrado; FBS = Financeiramente bem-sucedido com sobras e/ou aplicaçóes/ investimentos

Fonte: Elaborado pelos autores (2019).

De acordo com os dados apresentados na Tabela 4, constata-se que grande parte dos respondentes possui faixa de renda entre 2 a 4 salários mínimos (34\%), seguidos de 4 a 6 salários mínimos (23,4\%), ou seja, mais da metade dos profissionais que formaram a amostra da pesquisa apresentam faixa de renda entre 2 e 6 salários mínimos, desta forma, percebe-se ainda que são poucos aqueles que recebem abaixo de 2 salários mínimos (12,8\%) e mais de 8 salários mínimos (14,9\%).

Analisou-se ainda a percepção da situação financeira dos respondentes, devido ao fato de que em muitos casos, a tomada de decisão não é realizada de acordo com os valores recebidos, mas sim, conforme percepção do status quo. A grande maioria encontra-se financeiramente equilibrada, com 70,2\%, deste modo, possuem uma vida financeira estável.

Quanto à experiência profissional, percebe-se que os profissionais em sua grande maioria atuam a mais de 6 anos na área $(68,1 \%)$. Tal tempo de experiência pode fazer com que estes se considerem mais aptos e tenham maior clareza em uma tomada de decisão. A Tabela 5 aponta se o indivíduo é proprietário ou não da empresa em que atua, o tempo de atuação na empresa e a quantidade de colaboradores na empresa. 
Tabela 5 - Proprietário, tempo de atuação na empresa e quantidade de colaboradores

\begin{tabular}{|c|c|c|c|c|c|c|c|c|}
\hline \multirow{2}{*}{$\begin{array}{l}\text { Proprietário } \\
\text { Sim }\end{array}$} & \multicolumn{2}{|c|}{ Freq. (\%) } & \multirow{2}{*}{$\begin{array}{l}\text { Tempo de atuaçáo na } \\
\text { empresa }\end{array}$} & \multicolumn{2}{|c|}{ Freq. (\%) } & \multirow{2}{*}{$\begin{array}{r}\begin{array}{c}\text { Quantidade de } \\
\text { colaboradores }\end{array} \\
\text { Até } 10 \text { funcionários }\end{array}$} & \multicolumn{2}{|c|}{ Freq. (\%) } \\
\hline & 14 & $29,8 \%$ & & 11 & $23,4 \%$ & & 27 & $57,4 \%$ \\
\hline \multirow[t]{5}{*}{ Não } & 33 & $70,2 \%$ & De 6 a 10 anos & 10 & $21,3 \%$ & De 11 a 20 funcionários & 6 & $12,8 \%$ \\
\hline & & & De 11 a 15 anos & 7 & $14,9 \%$ & De 21 a 30 funcionários & 2 & $4,2 \%$ \\
\hline & & & De 16 a 20 anos & 4 & $8,5 \%$ & Mais de 25 funcionários & 3 & $6,4 \%$ \\
\hline & & & Mais de 20 anos & 5 & $10,6 \%$ & $\begin{array}{l}\text { Não atuam na área ou em } \\
\text { escritórios }\end{array}$ & 9 & $19,1 \%$ \\
\hline & & & $\begin{array}{l}\text { Não atuam na área ou em } \\
\text { escritórios ou com atuação } \\
\text { particular }\end{array}$ & 10 & $21,3 \%$ & & & \\
\hline Total & 47 & $100 \%$ & Total & 47 & $100 \%$ & Total & 47 & $100 \%$ \\
\hline
\end{tabular}

Fonte: Elaborado pelos autores (2019).

Observa-se que grande parte dos respondentes não são proprietários dos escritórios $(70,2 \%) \mathrm{em}$ que atuam como contador. Quanto ao tempo de atuação dos escritórios, nota-se que 44,7\% atuam na empresa até 5 anos. Em relação a quantidade de funcionários, identificou-se que 57,4\%\% dos escritórios são formados por até 10 colaboradores, entende-se deste modo, que os escritórios possuem estruturas enxutas de trabalho.

Ainda para a análise descritiva dos dados, verificou-se a tomada de decisão dos contadores em cada uma das questóes apresentadas a estes, para tanto, demonstra-se na Tabela 6 as decisóes de classificaçáo dos gastos com P\&D das cinco questóes que compunham o instrumento de coleta.

Tabela 6 - Decisóes de classificação dos gastos com P\&D

\begin{tabular}{|c|c|c|c|c|}
\hline Questáo & Ativo Intangível & Despesas & & Total \\
\hline 01 & $32 \quad 68,1 \%$ & $15 \quad 31,9 \%$ & 47 & $100 \%$ \\
\hline 02 & $17 \quad 36,2 \%$ & $30 \quad 63,8 \%$ & 47 & $100 \%$ \\
\hline 03 & $24 \quad 51,1 \%$ & $23 \quad 48,9 \%$ & 47 & $100 \%$ \\
\hline 04 & $31 \quad 66,0 \%$ & $1634,0 \%$ & 47 & $100 \%$ \\
\hline 05 & $28 \quad 59,6 \%$ & $19 \quad 40,4 \%$ & 47 & $100 \%$ \\
\hline
\end{tabular}

Fonte: Elaborado pelos autores (2019).

Observa-se na Tabela 1, que quatro das cinco questôes apresentaram preferência dos contadores em classificar os gastos com P\&D como ativo intangível. Apenas a questáo 02 apresenta preferência por classificar como despesa, talvez esta preferência tenha ocorrido pelo fato de que na questão apresenta-se a ausência do tempo de vida útil do site desenvolvido pela empresa, desta maneira, a contabilização da amortização seria impossibilitada.

A questão 01 foi a que teve maior preferência dos contadores na classificação em ativo intangível $(68,1 \%)$, o valor expressado na questáo pode ter sido o principal diferencial para tal escolha contábil (R\$ 1.000.000,00). Deste modo, a contabilização no ativo intangível proporciona um impulso do ativo da organizaçáo, caso contabilizado nas despesas, o efeito seria contrário, de modo a diminuir os lucros ou até 
mesmo ocasionar prejuízos à organização. Tal achado merece atenção para a categoria contábil, os quais devem seguir postura conservadora em suas tomadas de decisão de contabilização.

Também com grande força, a questão 04 apresentou preferência de 66\% dos participantes na classificação em Ativo Intangível, novamente o valor expressivo pode ter ocasionado tal reação ( $\mathrm{R}$ \$ $700.000,00$ ), outro fato pode estar associado a se referir a gastos com software. A questão 05 foi outra com destaque ao Ativo Intangível (59,6\%), nesta, a análise continuou na parte tecnológica, o que pode ter motivado tal preferência por contabilização em Ativo e não como despesas.

Por fim, a questão 03 foi a que apresentou o maior equilíbrio dentre as analisadas, para 24 participantes a contabilização deveria ser realizada como Ativo Intangível, já para os outros 23 participantes, a contabilização deveria ser feita como despesas. Nesta questão em especial, apresentou-se aos contadores os gastos com pesquisa e desenvolvimento de modo separado (Pesquisa = R \$ 300.000,00 e Desenvolvimento $=\mathrm{R} \$ 150.000,00)$, o que pode ter ocasionado o equilíbrio nas escolhas de classificação.

\subsection{Análise dos resultados}

Nesta seção é apresentado a análise dos resultados, utilizou-se o software R Studio para a elaboração dos cálculos estatísticos. Como no cálculo feito na Tabela 7 , sendo que se não apresenta ${ }^{*}$ p não tem evidência.

Tabela 7 - Análise quantitativa dos resultados

\begin{tabular}{|c|c|c|c|c|c|}
\hline QUESTÓES & Q01 & Q02 & Q03 & Q04 & Q05 \\
\hline \multirow{2}{*}{ Idade } & 0.190 & -0.044 & 0.064 & 0.008 & 0.129 \\
\hline & $(0.126)$ & $(0.115)$ & $(0.102)$ & $(0.109)$ & $(0.103)$ \\
\hline \multirow{2}{*}{ Gênero } & 0.902 & $-1.355^{*}$ & 0.057 & -1025 & -1171 \\
\hline & $(0.955)$ & $(0.818)$ & $(0.776)$ & $(0.826)$ & $(0.845)$ \\
\hline \multirow{2}{*}{ Grau de Instruçáo } & 0.205 & -0.292 & 0.152 & 0.761 & -0.746 \\
\hline & $(0.779)$ & $(0.627)$ & $(0.574)$ & $(0.649)$ & $(0.615)$ \\
\hline \multirow{2}{*}{ Faixa de Renda } & -0.044 & -0.350 & -0.327 & -0.029 & 0.755 \\
\hline & $(0.628)$ & $(0.523)$ & $(0.483)$ & $(0.519)$ & $(0.538)$ \\
\hline \multirow{2}{*}{ Situaçáo Financeira } & -0.749 & -0.530 & -0.630 & 0.368 & 0.173 \\
\hline & $(0.832)$ & $(0.671)$ & $(0.677)$ & $(0.674)$ & $(0.667)$ \\
\hline \multirow{2}{*}{$\begin{array}{l}\text { Experiência } \\
\text { Profissional } \\
\end{array}$} & -0.016 & 0.063 & 0.004 & -0.152 & -0.221 \\
\hline & $(0.164)$ & $(0.141)$ & $(0.128)$ & $(0.135)$ & $(0.135)$ \\
\hline \multirow{2}{*}{ Proprietário } & -0.624 & 0.991 & -0.558 & $2.835^{*}$ & -0.072 \\
\hline & -1496 & -1358 & -1269 & -1682 & -1241 \\
\hline \multirow{2}{*}{$\begin{array}{l}\text { Tempo de Atuação } \\
\text { no Escritório }\end{array}$} & $-0.198^{* *}$ & 0.056 & -0.079 & 0.007 & -0.052 \\
\hline & $(0.085)$ & $(0.061)$ & $(0.066)$ & $(0.057)$ & $(0.061)$ \\
\hline \multirow{2}{*}{$\begin{array}{l}\text { Quantidade de } \\
\text { Funcionários }\end{array}$} & 0.043 & -0.020 & 0.101 & 0.042 & 0.071 \\
\hline & $(0.045)$ & $(0.026)$ & $(0.079)$ & $(0.031)$ & $(0.054)$ \\
\hline
\end{tabular}

Nota: Dentre as variáveis acima descritas, entende-se o grau de significância como ${ }^{*} \mathrm{p}<0.10$ têm evidência sugestiva; ${ }^{* *} \mathrm{p}<0.05$ têm evidência moderada; $\mathrm{e}^{* * *} \mathrm{p}<0.01$ têm evidência forte. Q01 = Questão 01; Q02 = Questão 02; Q03 = Questão 03 ; Q04 = Questão 04; Q05 = Questão 05 . 
O modelo estatístico utilizado foi significante para se afirmar que foram encontradas evidências de que o gênero, se é proprietário do escritório e o tempo de atuação no escritório de contabilidade, interferem em algumas variáveis dependentes. Assim, foram encontradas evidências de que o fato de o respondente ser do gênero masculino aumenta a probabilidade de ele reconhecer como despesa os gastos com pesquisa e desenvolvimento. Uma das possíveis justificativas está relacionada ao fato que o gênero masculino pode ser mais conservador em uma tomada de decisáo, fato este que corrobora com Cappelle et al. (2004) e Gava e Vieira (2006), ao apontar que tal característica pode diferenciar os hábitos dos indivíduos, consequentemente, pode haver uma distinção na tomada de decisão.

Foram encontradas evidências ainda de que o respondente ao ser proprietário do escritório, aumenta a probabilidade de ele reconhecer como Ativo Intangível na questão 04, onde um dos possíveis motivos pode ser o fato de que ela apresentou valores monetários altos no investimento na criação de um novo software. $\mathrm{O}$ fato de o contador ser ou não proprietário do escritório está relacionado à responsabilidade do mesmo em relação a contabilização dos clientes. Entende-se que contadores que são os proprietários dos escritórios tendem a ser mais conservadores, uma vez que seriam diretamente responsabilizados em caso de erros de contabilização.

Encontraram-se evidências também de que quanto maior o tempo de atuação do escritório, maior a probabilidade de ele reconhecer como despesa na questão 01 . Deste modo, pode-se relacionar o fato de que um escritório com uma atuação consolidada no mercado de trabalho, possui mais experiência com algumas situaçôes que envolve tomadas de decisóes em relação a investimentos altos, onde na questão 01 apresentou um investimento de $\mathrm{R} \$ 1.000 .000,00$ (um milháo de reais), referente aos gastos com o desenvolvimento de um medicamento, onde demonstra a possibilidade de gerar benefícios econômicos futuros.

\subsection{Discussão dos resultados}

Verificou-se que três características demográficas dos contadores apresentam aumento relevante que influencia na probabilidade dos respondentes em optar por escolher mais uma resposta do que a outra. Estes achados devem realçar a atenção do profissional no momento da realização das escolhas contábeis, de modo a não se deixar influenciar por vieses que este possui em virtude de suas características particulares.

As características demográficas apresentadas como a idade, grau de instrução, faixa de renda, situação financeira, experiência profissional e quantidade de funcionários, pode não ter influenciado na probabilidade de optar em uma resposta mais do que a outra, pois essas características demográficas dos respondentes são mais variáveis, sendo assim, tais características não influenciam nas questôes apresentadas.

Foi verificado nos estudos relacionados, que há grau de significância no reconhecimento dos gastos com pesquisa e desenvolvimento. Constata-se que esses estudos analisam as companhias abertas da B3 e possuem relevância em seus resultados. No entanto, alguns destes estudos apresentam que tiveram dificuldades de encontrar informaçóes sobre reconhecimento dos gastos com pesquisa e desenvolvimento nas empresas analisadas. Neste caso, é possível que esses resultados obtidos, demonstram isto devido aos anos analisados. 


\section{Considerações finais}

O objetivo desta pesquisa foi de analisar se as características demográficas dos contadores influenciam no reconhecimento dos gastos de $\mathrm{P} \& \mathrm{D}$ como ativo intangível ou como despesa. Para que este fosse atingido, realizou-se análises estatísticas descritivas das características dos respondentes, bem como de suas opções na tomada de decisão na classificação das contas contábeis. Além disto, aplicou-se uma Regressão Logística para identificação das características que tinham influência significante para a escolha de contabilizar em Ativo Intangível ou despesa.

A relevância da pesquisa se dá por se tratar de gastos com P\&D, o qual está incluso no CPC 04 (Ativo Intangível) e ser um item de avaliação não padronizada pelas normas contábeis, ou seja, há subjetividade no momento de reconhecimento.

A partir da análise das características demográficas dos contadores e como estas influenciam no reconhecimento dos gastos de $\mathrm{P} \& \mathrm{D}$ como Ativo Intangível ou como despesa, observou-se que 3 (três) das 9 (nove) características demográficas independentes apresentadas influenciam na probabilidade de reconhecer os gastos da fase de pesquisa e desenvolvimento. Uma destas características foi o gênero, que apesar de haver 47 (quarenta e sete) respondentes, 22 (vinte e dois) foram masculinos e 25 (vinte e cinco) foram femininos, e foi o gênero masculino que teve influência relevante no reconhecimento como despesa na questão 02.

Se o respondente era proprietário ou não do escritório em que foi aplicado o questionário, foi a segunda característica demográfica que apresentou influência no reconhecimento dos gastos com pesquisa e desenvolvimento, que apesar de 29,8\% serem proprietários dos escritórios, houve relevância, aumentase deste modo, a probabilidade de ele reconhecer como Ativo Intangível na questáo 04, na qual um dos possíveis motivos pode ser o fato de que a mesma apresentou valores monetários altos no investimento na criaçáo de um novo software. A terceira característica demográfica que teve influência no reconhecimento foi o tempo de atuação do escritório, pode-se se ter essa influencia talvez porque o escritório já tenha se consolidado no mercado.

Por fim, conclui-se que a subjetividade deixada pelas normas contábeis faz com que o reconhecimento dos gastos com $\mathrm{P} \& \mathrm{D}$ não sejam padronizados entre os profissionais contábeis. Assim, esta pesquisa contribui tanto para a teoria, pelo pioneirismo na verificaçáo desta influência das características demográficas na classificação contábil, como à prática, por servir como alerta aos contadores, de modo entender as tomadas de decisóes dos contadores, bem como apresentar a importância da constante atualização e continuação da educação destes profissionais.

Sugere-se para pesquisas futuras, a ampliação da amostra ao aplicar a pesquisa a nível nacional, bem como a inclusão de outras características demográficas, para verificar se com uma amostra maior, com mais características podem influenciar no reconhecimento dos gastos com pesquisa e desenvolvimento como Ativo Intangível ou como despesa, a mesma pesquisa pode ser aplicada em outras áreas de conhecimentos. 


\section{Referências}

BARSCH, L. S.; SOUZA, M. M. Características da Evidenciação da Fase de Pesquisa e Desenvolvimento de Ativos Intangíveis nas Companhias de Capital Aberto Brasileiras. Revista de Contabilidade da UFBA, v. 12, n. 1, p. 137-156, 2018.

BEUREN, I. M.; THEISS, V.; SANT’ANA, S. V. Conservadorismo contábil no reconhecimento de ativos intangíveis em fase de pesquisa e desenvolvimento: um estudo em empresas da BM\&FBovespa. Revista Contabilidade, Gestáo e Governança, v. 16, n. 1, 2013.

BRASIL (1976). Lei no 6404, de 15 de dezembro de 1976. Disponível em: http://www.normaslegais. com.br/legislacao/contabil/lei6404_1976.htm. Acesso em: 18 de novembro de 2018.

BRASIL (2007). Lei no 11.638/07. Disponível em: http://www.planalto.gov.br/ccivil_03/_Ato20072010/2007/Lei/L11638.htm. Acesso em: 18 de novembro de 2018.

CAMARGO, T. F.; ZANIN, A.; DIEL, F. J.; BIANCHET, T. D. S. A. Influência da P\&D no desempenho de empresas: análise do bloco econômico G 20. In: Anais do Congresso Brasileiro de Custos-ABC. 2016.

CAPPELlE, M. C. A.; MELO, M. C. O. L.; BRITO, M. J. M.; BRITO, M. D. Uma análise da dinâmica do poder e das relaçóes de gênero no espaço organizacional. RAE-eletrônica, v. 3, n. 2, p. $1-17,2004$.

COMITÊ DE PRONUNCIAMENTOS CONTÁBEIS. (2011). CPC 00 (R2) - Estrutura Conceitual para Relatório Financeiro. Disponível em: http://static.cpc.aatb.com.br/Documentos/573_CPC00(R2). pdf. Acesso em: 18 de maio de 2021.

COMITÊ DE PRONUNCIAMENTOS CONTÁBEIS. (2014). Pronunciamento técnico cpc 04 (r1) ativo intangivel. Disponível em: http://static.cpc.aatb.com.br/documentos/187_cpc_04_r1_rev\%2013. pdf. Acesso em: 29 de outubro de 2018.

CUNHA, C. R.; COLARES, A. C. V. A ética profissional e o contador: Um estudo sobre a postura ética no exercício da profissão em escritórios de contabilidade. In: CONGRESSO UFSC DE CONTROLADORIA E FINANÇAS. 2014.

DAVEL, E.; VERGARA, S. C. Gestão com pessoas e subjetividade. 7 ed. Editora Atlas AS, 2014.

FÁVERO, L. P.; FAVERO, P. Análise de dados: modelos de regressão com Excel $^{\oplus}$, Stata $^{\circledast}$ e SPSS $^{\circledast}$. Elsevier Brasil, 2016.

FUJI, A. H.; SLOMSKI, V. Subjetivismo responsável: necessidade ou ousadia no estudo da contabilidade. Revista Contabilidade \& Finanças, v. 14, n. 33, p. 33-44, 2003.

GAVA, A. M.; VIEIRA, K. M. Tomada de decisão em ambiente de risco: uma avaliação sob a ótica comportamental. REAd-Revista Eletrônica de Administração, v. 12, n. 1, 2006. 
MARION, J. C. Normas e práticas contábeis. 2 ed. São Paulo: Atlas, 2013.

MELLO, L. C. O.; ARAUJO, P. G. L. O efeito da subjetividade na mensuração de itens patrimoniais a valor justo por setor econômico. In: Anais do Congresso Brasileiro de Custos-ABC. 2015.

OSHITA, M. G. B.; SANCHES, S. L. R.; IGARASHI, D. C. C.; IGARASHI, W. Análise dos Ativos Intangíveis em empresas brasileiras que utilizam benefício fiscal de incentivo à inovação. Revista de Estudos Contábeis, v. 7, n. 12, p. 23-38.

OTANI, N.; FIALHO, F. A. P. TCC métodos e técnicas. 2 ed. Florianópolis: Visual Books, 2011.

PADOVEZE, C. L. Manual da contabilidade básica: Contabilidade introdutória e intermediária. 10 ed. São Paulo: Atlas, 2017.

PORTAL DA CONTABILIDADE (2018). Dúvidas sobre o registro e profissáo contábil. São Paulo. Disponível em: www.portaldecontabilidade.com.br/tematicas/profissao_contabil.htm. Acesso em 18 de dezembro de 2018.

REIS, A. C. F. Economia criativa como estratégia de desenvolvimento: uma visão dos países em desenvolvimento. São Paulo: Itaú Cultural, 2008.

RESSER, C. A.; PEREIRA, S. C. O papel do contador como gestor organizacional: percepções e análises da contabilidade gerencial. Revista Eletrônica do Curso de Ciências Contábeis, v. 7, n. 1, p. 260-278, 2018.

RODRIGUES, J. M.; ELIAS, W. G.; CAMPOS, E. S. Relevância da Informação Contábil: uma análise dos efeitos da contabilização dos gastos com pesquisa e desenvolvimento com a aplicação da Lei 11.638/07 no mercado brasileiro. Revista Contabilidade e Controladoria, v. 7, n. 3, 2015.

SOUZA, E. A. F.; ASCENÇÃO, H. S.; SOUZA; I. B. (2011). Adequaçáo do Profissional de Contabilidade Junto as Novas Tecnologias dos Sistemas Integrados de Informaçáo. Manaus: UNILASALLE. Disponível em: https://meuartigo.brasilescola.uol.com.br/informatica/adequacaoprofissional-contabilidade-junto-as-novas-.htm. Acesso em 02 de setembro de 2018. 